KATARZYNA BIELA

D HTTP://ORCID.ORG/ 0000-0002-7392-2546

e-mail:kmbiela@gmail.com

Jagiellonian University

\title{
Is this Liberature? Words and Images in Sebald's The Rings of Saturn ${ }^{1}$
}

\begin{abstract}
The paper presents The Rings of Saturn as an example of liberature - a literary genre defined by Zenon Fajfer and Katarzyna Bazarnik that encompasses literary works in which authors purposefully fuse the content with the form and make use of the book as both a medium and an aesthetic object itself. The goal is to examine the relationship between words and images in the book to identify liberatic characteristics of Sebald's work. The analysis concentrates around descriptions of landscape, focusing on the narrator noticing particular objects against the plain coast as well as uniting nature and humankind in numerous digressions. A close reading of a few passages with reference to studies by i.a. Long, Jacobs and Cooke makes it possible to examine the narrator's relationship with nature and the historical concerns stemming from his complex national identity. Both are subsequently set against the whole narrative and the form of the book. The second part of the paper is devoted to a close analysis of a few photographs from The Rings of Saturn along with their impact on Sebald's overall message. A reference to Stockwell's studies on figures and backgrounds as represented in literature offers a cognitive perspective on the work's multimodal content .
\end{abstract}

Keywords: Sebald, The Rings of Saturn, liberature, words and images

What accompanied the end of the $20^{\text {th }}$ and the beginning of the $21^{\text {st }}$ century in literary studies was a realization that a book should be perceived and analysed not as a transparent medium for presenting text, but rather as a physical object whose shape influences the reading experience - the view proposed, for instance, by N. Katherine Hayles in Writing Machines (2002), Alison Gibbons in Multimodality, Cognition, and Experimental Literature (2012) and, following Zenon Fajfer (1999), Katarzyna Bazarnik's Liberature. A Book-bound Genre (2016). Gibbons is convinced that "even within mainstream publishing, the period surrounding the

1 Research financed from the budget for science and arts 2018-2022 as a research project being a part of the "Diamond Grant" programme / Praca naukowa finansowana ze środków budżetowych na naukę w latach 2018-2022, jako projekt badawczy w ramach programu „Diamentowy Grant”. 
turn of the millennium has seen an increase in the inclusion of typography and illustration in fiction for adults". ${ }^{2}$ In this way, she notices that the book has become a tool to exercise for meaning-making purposes, but also alludes to another feature of contemporaneity, namely the tendency to connect literature with visual arts. An example of the discussion on this juxtaposition is Stephanie Albers's Verbal Visuality (2011), in which the author analyses how contemporary authors of the Anglophone world make use of references to visual arts in their fiction. As she explains, her goal is to see how the two influence each other:

The study is not directed at stressing the notion of a 'mutual illumination of the sister arts' but aims at going one step further, intending to point out the mutual interdependence of the verbal and the visual in contemporary art narratives. The interdependence eventually leads to the creation of an iconotext or a hybrid text that often significantly goes beyond the semiotic potential of the traditional narrative text. ${ }^{3}$

Likewise, Grzegorz Maziarczyk in his discussion on VAS, Extremely Loud and Incredibly Close and House of Leaves states that the works "seem to respond to the predominantly visual character of contemporary culture [...] by probing the limits of verbal and visual representations and by suggesting the multimodal meaning-potential of word/image compounds"4.

In the number of literary works encouraging such a spatial and verbo-visual approach, W. G. Sebald's ouvre has its own unique place. Many of his works combine text with self-taken photographs testifying to the fact that the author consciously juxtaposes the two media: the decision about including the images is his own choice, not a publisher's strategy. Thus, the relationship between the narrative and the photographs seems to be more complex than that between a text and illustrations incorporated into it at the stage of designing a book. From this perspective, his works could be categorized as examples of liberature, a literary genre, in which the awareness of the book as a material entity and a semantically complex whole is a key element. Defined in 1999 by Zenon Fajfer and Katarzyna Bazarnik, the category encompasses literary works whose content and form are united in the way that they are both important means of expression.

Though Sebald's liberatic device, i.e. combining words and images, seems to be quite simple, he is an author who definitely reflects on the elements of his books as well as interrelations between them. The question is then what kind of liberatic author he is and what he achieves through his intermediality. Or, more specifically, how words and images interact in his works and what kind of A whole they eventually form. Addressing these issues, I will analyse The Rings of Saturn as an example of a liberatic work with the focus on the relationship between the narrative and the photographs. I find this work particularly interesting and useful in this context as the meditative character and the traveling theme prompt a suggestion that it could be a self-reflexive meditation and journey as well.

2 A. Gibbons, Multimodality, Cognition, and Experimental Literature, New York 2012.

3 S. Albers, Verbal Visyality. The Visual arts in Contemporary Anglophone Fiction, Trier 2011.

${ }^{4}$ G. Maziarczyk. Print Strikes Back. Typographic Experimentation in Contemporary Fiction as a Contribution to the Metareferential Turn [in:] The Metareferential Turn in Contemporary Arts and Media. Forms, Functions, Attempts at Explanation, ed. W. Wolf, Amsterdam, New York 2011. 


\section{Words}

\section{Figure against background}

The narrator of The Rings of Saturn (1995) explains what the story is going to be about in the very first sentence: "In August 1992, when the dog days were drawing to an end, I set off to walk the country of Suffolk, in the hope of dispelling the emptiness that takes hold of me whenever I have completed a long stint of work". 5 The reader is invited to join the narrator on his journey along the East Anglian coast and subsequently the act of opening the book resembles the act of departure. Although The Rings of Saturn can be read as an autobiography or a historical novel (Simon Cooke mentions "Fiction/History/Memoir/Travel"'), the wander is the most obvious and clear subject of the story. As Cooke states, "Die Ringe des Saturn is the most immediately recognizable as a travelogue". ${ }^{7}$ Despite that, the question of the narrator's agency as regards the choice of the explored area remains unanswered. Sebald was teaching at the University of East Anglia in Norwich at the time of travelling, so, as much as he may have liked Suffolk, he might have just as well decided to go there because of the spatial proximity. The idea of "dispelling the emptiness" along the coast seems a bit strange since the place does not offer many stimuli to fill in the mental blank. Daniel Weston mentions that "[c]hief among the characteristics of East Anglia's coastal areas upon which Sebald's thoughts are predicated are its flatness and low population density". ${ }^{8} \mathrm{He}$ continues to remark that "[t]hese features figure in his [the narrator's] reading of landscape as emptiness" that somehow begins to "interplay" with "the process of refilling". 9

Although the landscape is deserted, the narrator spots various objects both close to him and on the horizon. Once he states: "a sailing boat kept me company" 10 and another time "tent-like shelters" catch his attention and encourage him to reflect: "It is as if the last stragglers of some nomadic people had settled there, at the outmost limit of the earth, in expectation of the miracle long for since time immemorial, the miracle which would justify all their erstwhile privations and wanderings". ${ }^{11}$ In the description the plain coast becomes the end of the world, the East that so many wanderers tried to reach by following the sun. It is a peculiar microworld, with its own community of inhabitants affected by constant fluctuation of its members. J.J. Long notes that, by contrast, the objects guarantee certain stability: "tents remain constant in number despite the comings and goings of individuals". ${ }^{12}$ What he also notices in this passage is Sebald's "di-

5 Ibid.

6 S. Cooke, Travellers' Tales of Wonder Chatwin, Naipaul, Sebald, Edinburgh 2013.

Ibid.

8 D. Weston, The Spatial Supplement: Landscape and Perspective in W.G. Sebald's The Rings of Saturn, "Cultural Geographies" 2011, No. 2.

9 Ibid.

10 W.G. Sebald, op. cit.

11 Ibid.

12 J.J. Long, W.G. Sebald: Image, Archive, Modernity, Edinburgh 2007. 
gressive principle". ${ }^{13}$ Since the landscape is plain, "the narrator and the reader" get "sidetracked into lengthy enumerations of physical objects". ${ }^{14}$ This leads to reflection on their owners, especially when the narrator elaborates on the fact that the present fishermen only seem to form a group, but actually "each of them is nonetheless quite alone and dependent on no one but on himself [...]. They just want to be in a place where they have the world behind them, and before them nothing but emptiness". ${ }^{15}$ Surprisingly, in the following sentences, the people are no longer present and what the narrator is left with is a grim impression of decay and "abandoned boats that are falling apart". ${ }^{16}$ The people have escaped the coast because fishing appeared not enough for them to make a living, so there is no one who could properly welcome the narrator. He finds himself in a position of a latecomer facing the previously crowded, but for now desolate space.

The passage strikes with its strong tension between stasis and change. The description of empty landscape blends with the description of objects left behind by people who were there, but no longer are. The deserted place becomes cluttered and crowded in the narrator's mind for a while - an amount of time determined by his thinking process - until his reflections become melancholic and he finds himself lonely again. The fluctuating impressions seem to be in tune with waves and tides - the characteristics of the unstable sea. Nature seen through the narrator's eyes is so strongly connected to humans, the things they make and their cognitive abilities that it appears impossible to describe it separately. The landscape, though deserted, lives due to the processes of transformation and fluctuation, which in part take place in the wanderer's mind. As Carol Jacobs contends, whatever our interpretation of the passage, "Sebald's writing [...] goes by way of involuntary thought and brings us to the question of metamorphosis". ${ }^{17}$

The perception of landscape in The Rings of Saturn is a relative matter, which tells a lot about the narrator's act of "refilling" it. The image of fishermen looking at the sea is ambiguous as on one hand they are "gazing out to the sea as it changes before their eyes" 18 , but on the other they position themselves like this because they want to "have the world behind them". ${ }^{19}$ This brings us back to the question of agency, but also suggests that there are many different ways of perceiving and interpreting reality. Emptiness might sometimes be desirable, but it is also something the narrator tries to overcome through having a close look at landscape and directing attention to details. Reading the description from the perspective of cognitive poetics, the tents seen against the coast are figures visible against the background and they attract readers' attention due to their "newness"' 20 , that is due to the fact that they stand out from the plain coast. Depicting landscape in this way is a reason why The Rings of Saturn may appear interesting to readers because "one of the main functions of literature is to defamiliarise the subject-

\footnotetext{
3 Ibid.

4 Ibid.

5 W. G. Sebald, op. cit.

6 Ibid.

7 C. Jacobs, Sebald's Vision, New York 2015.

8 W.G. Sebald, op. cit.

9 Ibid.

20 P. Stockwell, Cognitive Poetics: an Introduction, London 2002.
} 
matter, to enstrange the reader from aspects of the world in order to present the world in a creative and newly-figured way". ${ }^{21}$

The success of "refilling" is questionable, though, because of the speculative character of the narrative. Long notices that the narrator uses expressions like "as if", "I imagine" and "In reality", which makes his account subjective and unreliable. ${ }^{22}$ The shifts of perspective discourage from treating Sebald's travelogue as a guide. All that is depicted could just as well be a projection or a literary device directing to another entity because "the textual transformation of one space into another is enabled by metaphor, and as such it forms part of a wider pattern of substitutions". ${ }^{23}$ For Cooke, such a manner of describing a place makes room for doubts about verisimilitude. To his mind, defamiliarisation with its effects, such as " $[\mathrm{t}]$ he atmosphere of marvels and monsters, extraordinary encounters and inexplicable incidents, in itself raises the question of the credibility of witness". ${ }^{24}$

\section{Individual against history}

The narrator of The Rings of Saturn wonders about the question of witness himself after he loses sight of the boat he called his "companion". ${ }^{25}$ The impression reminds him of a story from the Gospel in which St. Mark describes Jesus driving out demons from Gadarene and transferring them onto swine that later drown in the sea. The recollection, in turn, encourages him to ask multiple ethical questions:

Is this terrible story, I asked myself, as I sat overlooking the German Ocean, the report of a credible witness? If so, does that not mean that in healing the Gadarene Our Lord committed a serious error of judgement? Or was this parable made up by the evangelist, I wondered, to explain the supposed uncleanliness of swine; which would imply that human reasoning, diseased as it is, needs to seize on some other kind that it can take to be inferior and thus deserving of annihilation? ${ }^{26}$

The passage is another example of multiple shifts of tone and perspective. Nature reminds the narrator of the Bible, one of the earliest and the most fundamental cultural sources, which later brings him to ethical matters. Moreover, the story relates Jesus' decision about transferring demons through the evangelist's point of view, which makes its reliability ambiguous. What makes the excerpt even more complex is the interpolation about the German Ocean. Since the narrator reminded himself of the story when he was watching the North Sea from Suffolk, his eyes at that moment must have been directed towards the Netherlands, but also Sebald's home country, that is Germany.

This short intrusion allows another interpretation of the passage connected to the narrator's national identity. Jonathan White remarks that "[m] uch of Sebald's

\footnotetext{
21 Ibid.

22 J.J. Long, op. cit.

23 Ibid.

24 S. Cooke, op. cit.

25 W.G. Sebald, op. cit.

26 Ibid.
} 
writing, even that which charts real journey along the East Anglian coastline [...] harkens back in mental travel to the land of his birth". ${ }^{27}$ Born in 1944, Sebald was unavoidably influenced by the Second World War. ${ }^{28} \mathrm{He}$ was too young at the time to remember any events, but the tragedy and its aftermath left a great mark on his personality and identity: he "grew up in a land which had been considerably destroyed by the Allies, in particular its great cities" and which had faced "haunting realities of the Holocaust". ${ }^{29}$ Such a position bears similarities to the situation of the narrator in The Rings of Saturn. White notes that after the war was over the generation coming before Sebald tended to repress memories and preferred not to talk about the traumatic events. ${ }^{30}$ In consequence, the tragedy was something Sebald was aware of, but did not understand because there was no one to discuss it with him. Like the narrator spotting tents, he was a latecomer whose questions remained unanswered and kept coming back in his thoughts like recurring waves. The war was a subject which he might have left behind, following the fishermen who turned back to the land, but which he decided to confront despite the difficulties that come with the enterprise. As White states, "Sebald wanted to know the worst, and therefore felt impelled to study the largely repressed story". ${ }^{31}$ The gesture of turning his gaze from England to Germany suggests that he could not let the matter go despite the spatial distance, presumably illustrating the gap of misunderstanding between him and the previous generation. On the other hand, as White contends, such a perspective could have been helpful because it allowed him to distance himself from his homeland and live "his own intellectual and literary life" in England. ${ }^{32}$ Whatever the case, if we read the story of Gadarene in this particular context, it turns out that "some other kind" mentioned by the narrator may refer to the destroyed Germany or the victims of the Holocaust. His question is too general to privilege one of the interpretations over the other. It is even possible that it works both ways and that "[m]editations [...] raise for Sebald sharp questions about the Germany of his birth; both the destruction that is caused and that which was wrecked upon it". ${ }^{33}$

Despite this ambiguity, the narrator's thinking process and the narrative in this passage develop in a similar way to the description of the tents and fishermen. Again, the reflection is prompted by a wander along the coast and spotting an object (a disappearing boat) which are followed by an elaborate discussion on people, the history of humankind and ethical matters. What can be identified in both excerpts is 'Sebald's tendency to treat 'nature' and 'human nature' as synonyms" 34 , but the second passage makes it even more explicit that the narrator seeks for his own place in the world through relating the reflections to himself and

27 J. White, Mental Travel and Memory Mapping in Sebald's Work, "CLCWeb: Comparative Literature and Culture" 2012, No. 5.

28 Ibid.

29 Ibid.

30 Ibid.

31 Ibid.

32 Ibid.

33 Ibid.

34 D. Weston, op. cit. 
attempting to make sense of his national identity. The history of his own country influences him to the extent that he takes the tragedies with him wherever he goes. He cannot deny his origins, which seem to function as lens through which he looks at reality and that is also where the question about "the credibility of witness" may come from. ${ }^{35}$ Cooke describes it even as one of Sebald's "abiding obsessions": "[T]he questions of the reliability of witness and the ways in which horizons of expectation prefigure what the observer encounters" remain the author's major concerns throughout the whole work. ${ }^{36}$

\section{Images}

Credibility and the renewal of the figure-background relationship is also characteristic of the physical shape of The Rings of Saturn because Sebald incorporates into his text self-taken photographs, pictures from external sources, reproductions of paintings and reprints from magazines among others. It is as if the textual background was repeatedly made fresh due to the visual interpolations. Each of the entries is linked to the narrative in a certain way and one of their functions is to add credibility to the convoluted story. When Long relates the opinion expressed by Sebald in different interviews, he mentions that the writer liked "to stress the authenticating function of images". ${ }^{37}$ However, "[b]y his own admission, some of them are intended to create uncertainty in the reader as to the authenticity of the text". ${ }^{38}$ Cooke agrees with this assumption when he discusses the photograph of a street in Lowestoft ${ }^{39}$ (fig. 1). He remarks that it is very helpful for a reader to look at a picture of the place she is reading about, but it is at the same time very confusing to have the narrator reflecting on loneliness ("Not a living soul was about in the long streets I went through" ${ }^{40}$ ) and to spot a couple of people in the right bottom corner of the image. An even more striking example of such an ambiguity accompanies the reference to the article about the death of Major Le Strange. The narrator talks about how the major's regiment saved the camp at Bergen Belsen and compliments the story with a photograph of the place spread across the two following pages (fig. 2). As Cooke points out, the image looks like "a pastoral scene" until the readers become aware of the corpses strewn under the trees. ${ }^{41}$

\footnotetext{
35 S. Cooke, op. cit.

36 Ibid.

37 J.J. Long, op. cit.

38 Ibid.

39 S. Cooke, op. cit.

40 W.G. Sebald, op. cit.

41 S. Cooke, op. cit.
} 
the formations of bombers, Lancasters and Halifaxes, Liberators and Flying Fortresses, going out towards Germany across the grey North Sea, and then straggling home in the dawn. In early April 1945, not long before the War ended, said Hazel, sweeping up the vine shoots he had cut, I saw two American Thunderbolts crash here, over Somerleyton. It was a fine Sunday morning. I had been helping my father with an urgent repair job up on the campanile, which is really a water tower. When we were finished we stood on the look-out platform, from where there is a view right out to sea. We had hardly had time to look around when the two planes, returning from a patrol, staged a dogfight over the estate, out of sheer high spirits, I suppose. We could see the pilots' faces clearly in their cockpits. The engines roared as they chased after each other, or flew side by side in the bright spring air, till their wing tips touched as they banked. It had seemed like a friendly game, said Hazel, and yet now they fell, almost instantly. When they disappeared beyond the white poplars and willows, I went all tense waiting for the crash. But there were no flames or clouds of smoke. The lake swallowed them up without a sound. Years later we pulled them out. Big Dick, one of the airplanes was called and the other Lady Loreley. The two pilots, Flight Lieutenants Russel P. Judd from Versailles, Kentucky, and Louis S. Davies from Athens, Georgia, or what bits and bones had remained of them, were buried here in the grounds.

After I had taken my leave of William Hazel I walked for a good hour along the country road from Somerleyton to Lowestoft, passing Blundeston prison, which rises out of the flatland like a fortified town and keeps within its walls twelve-hundred inmates at any one time. It was already after six in the evening when I reached the outskirts of Lowestoft. Not a living soul was about in the long streets I went through,

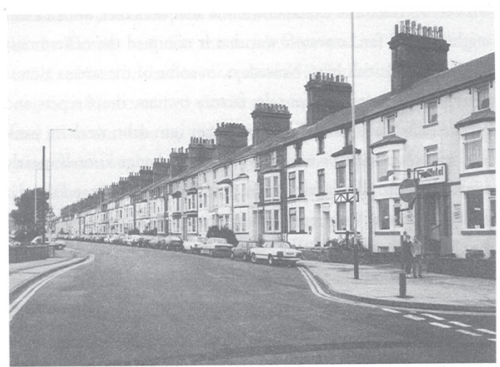

and the closer I came to the town centre the more what I saw disheartened me. The last time I had been in Lowestoft was perhaps fifteen years ago, on a June day that I spent on the beach with two children, and I thought I remembered a town that had become something of a backwater but was nonetheless very pleasant; so now, as I walked into Lowestoft, it seemed incomprehensible to me that in such a relatively short period of time the place could have become so run down. Of course I was aware that this decline had been irreversible ever since the economic crises and depressions of the Thirties; but around 1975, when they were constructing the rigs for the North Sea, there were hopes that things might change for the better, hopes that were steadily inflated during the hardline capitalist years of Baroness Thatcher, till in due course they collapsed

Fig. 1. W.G. Sebald, The Rings of Saturn, transl. M. Hulse, London 2002.

This examples demonstrates how "photographs are able to produce an experience of historical shock" ${ }^{42}$, but also presents reading of images in The Rings of Saturn as a cognitive challenge similar to the task set by Sebald in the narrative. In the introduction to the discussion on cognitive poetics Peter Stockwell includes a sketch of a cube and explains that it "can be seen either as a box on the floor or as a top corner of a room where the walls meet the ceiling [...] you can flip your perception from one view to the other, reversing the figure that you see with everything else that is in the background". ${ }^{43}$ Sebald's readers seem to be provided with an opportunity for a similar experience. They can either focus on the forest or on the dead bodies and they can repeatedly shift their attention from one interpretation to another. However, this process is much more than a cognitive puzzle because of its historical context and the emotions it provokes. What happens when the readers' attention shifts may allude to the narrator's position as a representative of a generation coming right after the Second World War. According to Long, "[a]s Sebald sees it, public memorial culture in Germany offers the second-generation subject insufficient material and narrative resources for the kind of imaginative investment and creation that are the prerequisites of postmemory". ${ }^{44}$ Similarly to the reflection on the war's tragic events related to the

\footnotetext{
42 J.J. Long, op. cit.

43 P. Stockwell, op. cit.

44 J.J. Long, op. cit.
} 


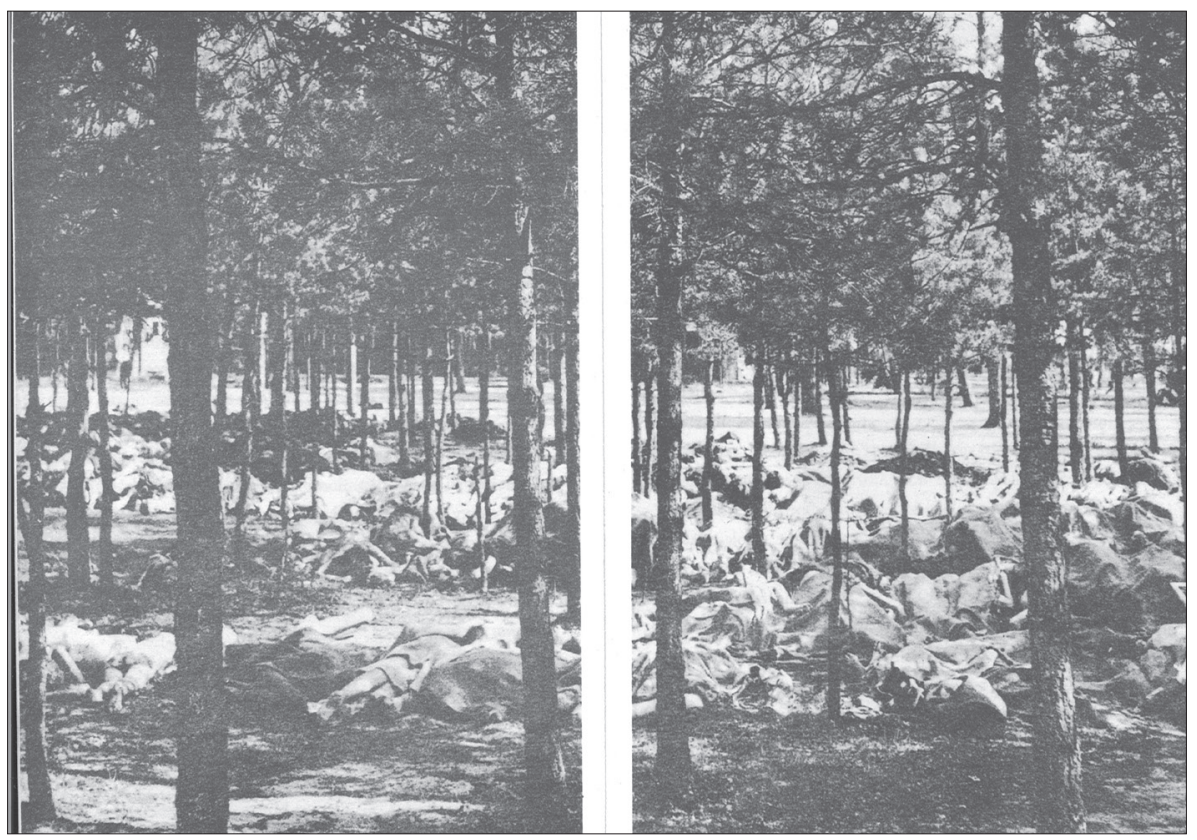

Fig. 2. W.G. Sebald, The Rings of Saturn, transl. M. Hulse, London 2002.

story of Gadarene, the commentary here is only suggested. The Rings of Saturn breaks the taboo connected with the Holocaust and other tragedies through gentle hints presumably because "[t]he narrator is confronted with material traces of a past that he does not understand". ${ }^{45}$ In spite of that, his desire "to know the worst" 46 is satisfied to a certain extent as readers are unlikely to forget about the corpses once they notice them on the ground. Although the story of Le Strange develops into a lighter tale concerned with his housekeeper, it is unlikely that the readers will easily get over the shock the image can evoke. This instance of Sebald incorporating an image into the narrative foregrounds also the motif of unity between nature and humankind, which we have identified as prominent in the narrative. In this way the blend of the physical form of the book and the text appears to be even more sophisticated.

In this example, defamiliarisation that accompanies the reading of the image lies in spotting a detail set against the background, but in the numerous instances of supporting the narrative with visual content in The Rings of Saturn, we can also find a case demonstrating the reverse process. In the first part of the work when a description of the dissection of a body in Amsterdam follows the narrator's reflection on Thomas Browne, the narrative is complemented by a reproduction of

\footnotetext{
45 Ibid.

46 J. White, op. cit.
} 
Though the body is open to contemplation, it is, in a sense, excluded, and in the same way the much-admired verisimilitude of Rembrandt's picture proves on closer examination to be more apparent than real. Contrary to normal practice, the anatomist shown here has not begun his dissection by opening the abdomen and removing the intestines, which are most prone to putrefaction, but has started (and this too may imply a punitive dimension to the act) by dissecting the offending hand. Now, this hand is most peculiar. It is not only grotesquely out of proportion compared with

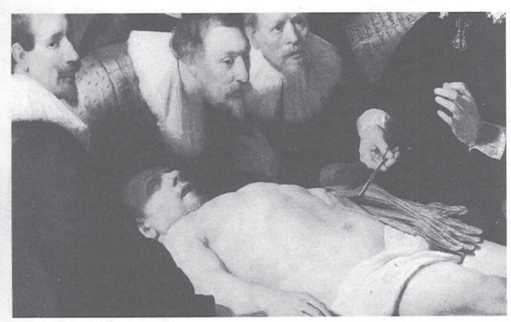

the hand closer to us, but it is also anatomically the wrong way round: the exposed tendons, which ought to be those of the left palm, given the position of the thumb, are in fact those of the back of the right hand. In other words, what we are faced with is a transposition taken from the anatomical atlas, evidently without further reflection, that turns this otherwise true-to-life painting (if one may so express it) into a crass misrepresentation at the exact centre point of its meaning, where the incisions are made. It seems inconceivable that we are faced here with an unfortunate blunder. Rather, I believe that there was deliberate intent behind this flaw in the composition. That unshapely hand signifies the violence that has been done to Aris Kindt. It is with him, the victim, and not the Guild that gave Rembrandt his commission, that the painter identifies. His gaze alone is free of Cartesian rigidity. He alone sees that greenish annihilated body, and he alone sees the shadow in the half-open mouth and over the dead man's eyes.

We have no evidence to tell us from which angle Thomas Browne watched the dissection, if, as I believe, he was among the onlookers in the anatomy theatre in Amsterdam, or indeed what he might have seen there. Perhaps, as Browne says in a later note about the great fog that shrouded large parts of England and Holland on the 27 th of November 1674, it was the white mist that rises from within a body opened presently after death, and which during our lifetime, so he adds, clouds our brain when asleep and dreaming. I still recall how my own consciousness was veiled by the same sort of fog as I lay in my hospital room once more after surgery late in the evening. Under the wonderful influence of the painkillers coursing through me, I felt, in my iron-framed bed, like a balloonist floating weightless amidst the mountainous clouds towering on every side. At times the billowing masses would part and I gazed out at the indigo vastness and down into the depths where I supposed the earth to be, a black and impenetrable maze. But in the firmament above were the stars, tiny points of gold speckling the barren wastes. Through the resounding emptiness, my ears caught the voices of the two nurses who took my pulse

17

Fig. 3. W.G. Sebald, The Rings of Saturn, transl. M. Hulse, London 2002.

Rembrandt's painting of this very dissection. ${ }^{47}$ Similarly to the image of Bergen Belsen, this picture takes up two pages. It goes along with the critique of privileging schemas over reality, which the narrator finds characteristic of Descartes and other scientists of Enlightenment. ${ }^{48}$ As the narrative progresses, the readers are also provided with a close-up of the dissected hand, which apparently seems to help them notice details in the part of the painting the narrator focuses on (fig. 3). However, what actually happens is that the image supports the narrator revealing mistakes in the representation of the body: "Now, this hand is most peculiar. It is not only grotesquely out of proportion compared with the hand closer to us, but it is also anatomically the wrong way round". ${ }^{49}$ He appreciates that Rembrandt left such a subtle surprise for attentive viewers and believes that the painter's perspective was "free of Cartesian rigidity". ${ }^{50}$ In effect, the close-up emphasises the narrator's view, but its purpose is to foreground his negative commentary. As helpful as

\footnotetext{
47 W.G. Sebald, op. cit.

48 Ibid.

49 Ibid.

50 Ibid.
} 
the image is, it actually points to the faults of science and philosophy, thus making the description of the dissection even grimmer and more complicated. To Jacobs's mind, the passage reveals that "[a]n overall cloudiness in perception means we fail to read any sign that haze might engulf, which may or may not be reason for melancholy". ${ }^{51}$ Here again, the image influences the narrative in an ambiguous way and the readers are encouraged to make cognitive effort in order to gain more from their reading experience.

\section{More than meets the eye}

The relationship between the detail and the background, the unity of nature and humankind as well as the concern with history and the tragedies of the Second World War can be identified as recurrent themes both in the narrative and in the visual content of The Rings of Saturn. The images come into play with words, which testifies that the visual content of the book is definitely not a set of illustrations, but a means of generating a dialogue between different modalities. Yet, as we saw in the analysis of the narrative, the wanderer and his journey remain in the centre of the story unfolding progressively despite digressions, which emphasises the importance of the textual layer. ${ }^{52}$ This already shows that Sebald's work is liberatic, but it seems that the characteristics of his prose make it possible to push this argument even further.

Since the relationship between words and images in The Rings of Saturn is complex and ambiguous, Cooke suggests that "the meaning of the juxtaposition" of the two "lies in the space between narrative and image". ${ }^{53}$ In his opinion, "[t]he consciousness of the mediatedness, both visually and textually [...] points outside its own frame of reference towards that which cannot be captured". ${ }^{54}$ This is in tune with Murray's assumption that one of the questions Sebald faces is concerned with "how to represent and engage with that which is unspeakable". ${ }^{55}$ It seems then than Sebald's works originated in a struggle that marked also the beginnings of liberature. The in-between position, especially in the context of birth and death, was what Zenon Fajfer and Katarzyna Bazarnik tried to capture in Oka-leczenie. As Fajfer explains:

I hit upon the idea of un-seeable/invisible literature in 1993 in un-usual in-comparable circumstances: when I witnessed my father's death, and soon after the birth of my son. It was then that I fully realized the obvious fact that such events as death and birth could not be adequately described, that words alone could not convey their essence even in some part,

51 C. Jacobs, op. cit.

52 R.T. Gray, Sebald's Segues: Performing Narrative Contingency in The Rings of Saturn, "The Germanic Review” 2009, No. 84.1.

53 S. Cooke, op. cit.

54 Ibid.

55 S. Murray, Fields of Association: W. G. Sebald and Contemporary Performance Practices [in:] A Literature of Restitution: Critical Essays on W.G. Sebald, eds. J. Baxter, V. Henitiuk, B. Hutchinson, Manchester 2013. 
and that perhaps, that could be expressed only through form but, alas, such a form did not even exist. ${ }^{56}$

Another point of comparison is the performative aspect of Sebald's prose and its potential to encourage cognitive participation on the part of the reader. Setting the writer's work against the practices of contemporary performers, Murray contends that one of the features they have in common is "the nature of the engagement sought with readers or audiences [...]. For Sebald, destabilizing reception and straining the reader's imagination takes a number of forms, which include: the juxtaposition of text and image" among other strategies. ${ }^{57}$ He even compares Sebald to Kantor ${ }^{58}$, an artist who influenced Fajfer and Bazarnik to great extent. The former wishes writers made conscious use of the space provided by a book in a way e.g. Kantor and Grotowski exercised the theatrical space ${ }^{59}$, while the latter treats a book as a "performative space" and foregrounds the active participation the reader takes in confrontation with liberature. ${ }^{60}$

\section{Conclusions}

After a close reading of the chosen passages from The Rings of Saturn, a close look at sample images from the book as well as identifying some of the common concerns Sebald shares with Fajfer and Bazarnik, it seems that analysing the work in the context of liberature highlights three characteristics of Sebald's writing and thinking about the book. First of all, the relationship between the figure and the background he consistently explores both in the narrative and the photographs points to his awareness of the book as a whole constituted of parts. He seems to be the kind of an author who plans his work in the very detail, while not losing the general view, which lets him tell how the fragments interact with one another and what is the final effect they give. Secondly, he appears to be fond of exploring the dynamics within the narrative, that is the interplay between themes, but also the way a given event or digression is introduced and later dismissed to make space for another subplot. The motif of a wander along the coast, which functions as a structuring device, prompts to view Sebald as a writer caring about the musical quality of his prose and, in general, the whole work, as if subsequent parts of the verbo-visual narrative borrowed some characteristics from the waves seen and heard by the narrator. Moreover, the juxtaposition of long, meditative sentences and the photographs, the former being regularly broken by the latter, could be seen as a technique inviting the reader to be attentive, alert and aware that she is reading a book that will challenge her reading habits. And thirdly, it is interesting

56 Z. Fajfer, Liberature or Total Literature (Appendix to the "Appendix to the Dictionary of Literary Terms”) [in:] Liberature or Total Literature. Collected Essays 1999-2009, ed. and transl. K. Bazarnik, Kraków 2010.

57 S. Murray, op. cit.

58 Ibid.

59 Z. Fajfer, Liberature or Total Literature...

60 K. Bazarnik, op. cit. 
to note what kind of liberature Sebald proposes. He was well aware of the medium, yet the form of The Rings of Saturn is not really extravagant. The narrative is rendered in prose alone and the style remains consistent throughout the whole story. Besides, the text, though broken by images, is arranged rather traditionally in a bound book suggesting linear reading. This is made ambiguous due to digressions, yet still Sebald's liberature is subtle - expressive, but not expressionist.

\section{Acknowledgements}

I am grateful to the Wylie Agency and the Estate of W.G. Sebald for the permission to reprint the spreads as well as to the anonymous reviewers for their very helpful suggestions. I would also like to thank Dr George Hyde (UEA), Dr Jos Smith (UEA) and prof. Katarzyna Bazarnik (JU) for supporting me on the way of writing this paper.

\section{Bibliography}

Bazarnik K., Liberature. A Book-bound Genre, Kraków 2016.

Cooke S., Travellers' Tales of Wonder Chatwin, Naipaul, Sebald, Edinburgh 2013.

Fajfer Z., A Brief History of Liberature (with Katarzyna Bazarnik) [in:] Liberature or Total Literature. Collected Essays 1999 - 2009, ed. and transl. K. Bazarnik, Kraków 2010.

Fajfer Z., Liberature or Total Literature (Appendix to the "Appendix to the Dictionary of Literary Terms") [in:] Liberature or Total Literature. Collected Essays 19992009, ed. and transl. K. Bazarnik, Kraków 2010.

Gibbons A., Multimodality, Cognition, and Experimental Literature, New York 2012.

Gray R.T., Sebald's Segues: Performing Narrative Contingency in The Rings of Saturn, "The Germanic Review" 2009, No. 84.1.

Jacobs C., Sebald's Vision, New York 2015.

Long J.J., W.G. Sebald: Image, Archive, Modernity, Edinburgh 2007.

McCloud S., Understanding Comics: The Invisible Art, New York 1994.

Murray S., Fields of Association: W.G. Sebald and Contemporary Performance Practices [in:] A Literature of Restitution: Critical Essays on W.G. Sebald, ed. J. Baxter, V. Henitiuk, B. Hutchinson, Manchester 2013.

Przybyszewska A., Liberackość dzieła literackiego, Łódź 2015.

Sebald W.G., The Rings of Saturn, transl. Michael Hulse, London 2002.

Stockwell P., Cognitive Poetics: An Introduction, London 2002.

Weston D., The Spatial Supplement: Landscape and Perspective in W.G. Sebald's The Rings of Saturn, "Cultural Geographies" 2011, No. 2.

White J., Mental Travel and Memory Mapping in Sebald's Work, "CLCWeb: Comparative Literature and Culture" 2012, No. 5. 
